\title{
Columbus Surpassed: Biophysical Aspects of How Stingless Bees Place an Egg Upright on Their Liquid Food
}

\section{B.-J. Velthuis}

Depto. de Ecologia, Instituto de Biociências, Universidade de São Paulo, Brazil

\section{H.H.W. Velthuis}

Depto. de Ecologia, Instituto de Biociências, Universidade de São Paulo, Brazil; and Vergelijkende Fysiologie, Universiteit Utrecht, Padualaan 14/ Postbus 80.086, 3508 TB Utrecht, the Netherlands

Received: 7 October 1997 / Accepted in revised form: 15 March 1998

The highly eusocial stingless bees (reviewed in $[1,2])$ constitute a phylogenetically old group [3] within the Apidae. Probably related to this ancient origin is their mass provisioning of brood cells: they deposit all the food on which the larva will develop into the brood cell, prior to oviposition and subsequent closure of the cell.

The other social members of the Apidae, the honeybees and the bumblebees, regularly visit the larvae in their cells to administer small amounts of liquid food at a time. This system is called progressive provisioning. Mass provisioning is practiced by almost all the other bees. However, while most of them have a solid type of larval food, the stingless bees produce a liquid food. In relation to this, their cylindrical brood cells are constructed vertically and are often arranged in horizontal combs. The food, regurgitated from the stomach, consists of a mixture of pollen, nectar, and glandular secretions $[1,2,4]$. After the workers have put this liquid food into the cell, the queen oviposits. Her egg,

Correspondence to: H.H.W. Velthuis, Utrecht with its elongated shape, stands upright on the fluid.

For its respiration, the egg, and the larva, needs to be in contact with air. Mass provisioning a solid food, as well as progressive provisioning, allows for the egg and the larva to maintain such contact, but the stingless bees need to solve this particular problem. The problem first appears in oviposition: how does the queen protect the egg from submergence? In our attempt to understand how stingless bees manage to keep their eggs in a vertical position, we studied some eggs and brood cells of Melipona bicolor bicolor Lepeletier, one of the larger stingless bees. A recently constructed piece of comb was taken from the colony, and the lid of a cell and part of its side wall were removed. This allowed us a lateral view of the egg and at the surface of the food. We used a binocular microscope, which we turned on its back to provide us with this horizontal view. The egg of this bee has an oval shape, about 2.5 times longer than wide, and is widest at two-thirds of its length relative to its base. The dimensions are approximately $2.7 \times 1.05 \mathrm{~mm}$. When the queen places her egg vertically onto the food, the broadest part is pointing upwards. The egg sinks into the fluid for only about one- seventh of its length, and for only $5 \%$ of its volume (see Fig. 1a). The egg is placed in the center of the brood cell, without having contact with the cell wall. Here it stands in wait for the larva to hatch, about five days later.

The position of the egg on the fluid is well-balanced. When we glued a hair of an eyelid onto a toothpick, we had an instrument with which to push the egg into an oblique position. It returned to its vertical position as soon as we released the pressure. When we hit the egg with the same instrument, it vibrated as though fixed onto a gelatinous surface. However, the food is a rather liquid one. Also, when the comb with eggs was held at an angle of $45^{\circ}$ the eggs would not fall. Only in combination with an abrupt movement did this disturb the equilibrium, so that the eggs came to lay flat on the food surface.

In a number of cases we found, upon opening the brood cell, part of the

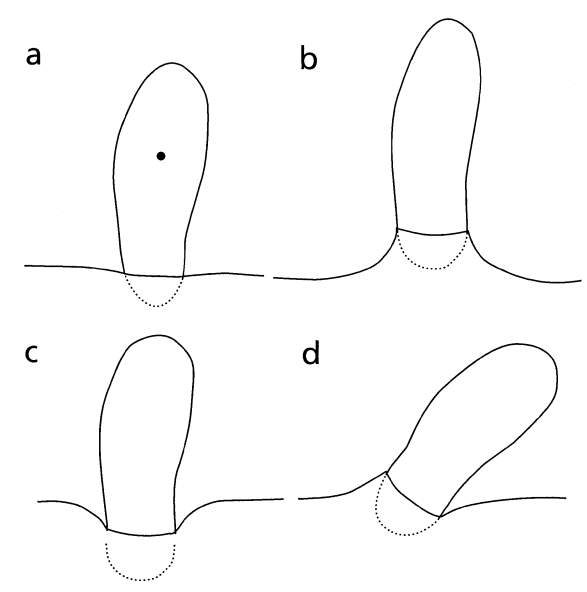

Fig. 1. a) Outline of an egg, as placed inside a cell by a M. bicolor bicolor queen. The location of the egg's point of gravity (dot) was estimated graphically. b) When the egg is lifted from the surface, the fluid adheres strongly to the base of the egg. c) When the egg is pushed slightly into the fluid, the meniscus bends downward, along with the egg's rim. d) When the egg is in an oblique position, this rim is tilted, and the fluid is lifted at one side of the egg, while pulled downward at the other side 
food surface to be covered with froth. In order to learn whether the amount of froth is related to the age of the cell, we followed the construction of a new comb, and noted at a 10- to 14-h interval, the occurrence of oviposition and cell closure for each brood cell. After 6 days the comb was taken from the colony, and a total of 30 cells of distinct age, with their eggs, were inspected. In all cells up to an age of 3.5 days, froth covered $10-90 \%$ of the food surface. In cells older than 3.5 days the froth had apparently disappeared. We conclude therefore that apart from a possible fermentation process [5] the froth is a consequence mainly of air being trapped in the food when the workers provision the cell. After the second day the food separates into a clear, liquid top layer and an opaque, yellowish bottom layer, due to sedimentation of the pollen. After 4 days the fluid on top constitutes about one-third of the food volume.

Clear fluid was sampled from the cells, and with the use of a refractometer its refraction was measured to equal a sugar concentration of $43 \%$ (range $39.4-47.4 \%, n=23$ ). In some of these 30 cells we found the egg in an oblique, or even in an almost horizontal position, although we had carefully manipulated the comb. In 15 cells the egg stood free from the wall, sometimes at an angle of $45-60^{\circ}$ with respect to the fluid. In 10 cases the egg made contact with the wall, generally just touching it, while in a more or less upright position, but in 3 cases the egg leaned firmly against it.

In three cells we found a larva about to hatch, and two of the cells we had damaged, so that the original position of the egg could not be determined. The position of the egg was not related to age, and one of the emerging larvae was still in a vertical position, free from the wall.

During oogenesis the egg of a bee is surrounded by an epithelium of follicular cells. These cells secrete a substance into their intracellular spaces, and towards the oocyte. In this way the chorion is formed. At the end of oogenesis the thus formed intracellular ridges between the follicular cells are thickened while the follicular cells themselves disappear. The egg has ac- quired a reticulate chorion structure on its outside, except at its lower end [6-8], where the egg remains perfectly smooth. We hypothesized the egg's reticular part to be lipophilic, its bottom part to be hydrophilic, and that this could play a role in the equilibrium of the egg on the larval food.

In order to test this we used an instrument essentially consisting of a glass capillary, connected to a narrow polyethylene tube. By means of a micromanipulator the capillary could be moved along each of three perpendicular axes. We filled the polyethylene tube, but not the glass capillary, with water. The tube was run between two metal rolls that compressed it; by rolling the tube in either direction we could exert sucking or pressing forces at the capillary mouth. This end of the capillary we had carefully heated with the flame of a cigarette lighter until it obtained the desired shape. The capillary's outer diameter was $2 \mathrm{~mm}$, narrowed down to $1.4 \mathrm{~mm}$ at the tip, while the inner diameter of its mouth was $0.3 \mathrm{~mm}$.

With a droplet of liquid, being paraffin oil or water, placed in its mouth, we could position the capillary above an egg, standing in the brood cell, and make contact, using the liquid as the intermediate. By manipulation of the position of the capillary's mouth relative to the top of the egg, meanwhile enlarging or diminishing the size of the protruding droplet, we could drag the egg along the surface of the food, put it upright when it was tilted, and suck the utmost top of the egg neatly against the glass. This made it possible to lift the egg from the food, to put it back again, or, to transfer it to other liquid surfaces, such as sugar solutions of various concentrations. The suction force even proved strong enough for us to push the egg completely under the surface of the liquid, without losing control over the egg.

The possibility of moving, and especially transplanting the egg, was slightly better when we used distilled water in the capillary mouth in comparison to the use of paraffin oil. We observed that paraffin oil would readily flow over the top of the egg, whereas water did not. Also, water could easily be removed completely by suction, with the mouth of the capillary at some distance from the egg. In contrast, when we lifted an egg from its food, the base often carried a film of liquid on its outside. These facts seem to support our hypothesis of a lipophilic character of the reticular structure, and a hydrophilic base of the egg.

With an egg affixed to the capillary and hanging free from the food, we could observe its base. Putting the egg between a light source and our binocular microscope, we discovered underneath the smooth surface of the egg's base similarly heavy intracellular ridges as occur in the reticular part of the chorion. With this translucent illumination the structure of the egg's base and that of its upper part became indistinguishable. It was only in a tangential view of the egg's surface that a change from the smooth base into the reticular structure was clearly visible. In scan electron microscopic pictures [6-8] the intracellular ridges that we observed under the smooth surface of the egg's base do not show up.

To study the nature of the materials at the exterior of the egg we submersed eggs in a $0.02 \%$ aquous solution of neutral red. This vital stain accentuated the reticular structure, but also slightly colored the smooth base of the egg. This demonstrates that these parts are composed of similar components. At closer examination, we noticed that the staining solution formed a film over the cells of the reticular structure, enclosing little air bubbles. When the film broke, the stain accumulated at the rims. Such a concentration of the stain of course did not occur at the smooth surface of the egg's base.

We suggest therefore that the smooth surface represents part of the follicular epithelium where the cells are probably still alive, while the reticulate structure is a part where the cells have died. After lifting the egg out of its cell we could place it once again on a liquid surface, in an Eppendorf cuvet. The transparency of the cuvet allowed for a clear view of both the upper and the submerged part of an egg, as our eyes skimmed the surface of the fluid. Once we completely submerged an egg in distilled water for 
several minutes. After this we let the egg dry in air. Finally, we placed the egg back onto the fluid, where it stood free, as though it had never been submerged. This stunning characteristic of an egg was lost, however, when we had submerged the egg, but only briefly, in $90 \%$ alcohol. When we tried to place such an egg back onto the surface, the egg sank immediately. Apparently the alcohol had changed the lipophilic character of the reticular structure.

In these Eppendorf experiments we observed that: (a) In lifting the egg the liquid around its basal part was also lifted, until the egg's contact with the food was suddenly lost. (b) When we pushed the egg slightly downward, the meniscus of the food bent inward with the egg. (c) When we put the egg in an oblique position, the meniscus was lifted at one side while it was pulled downward at the opposite side of the egg (see Fig. 1b-d). These observations demonstrate the presence of a sharp rim; this rim corresponds with the abrupt transition from reticulate to smooth surface. (d) When we pushed the egg further down, the upper part of the egg, now below the surface, captured tiny air bubbles, enclosed within the cavities of the reticular structure. While attempting to completely submerge the egg, it sometimes slid away as contact between the capillary mouth and the egg was lost. In such a case the egg floated to the surface.

As mentioned above, we succeeded in transfering eggs from their cells onto sugar solutions. We had put these solutions $(0 \%, 15 \%, 30 \%$, and $45 \%)$ in plastic vial caps with a $2.5-\mathrm{cm}$ inner diameter. We presumed the surface of such a solution to be perfectly horizontal in the center of these caps, but when we used excess volume of liquid, obviously the surface was clearly convex at the caps rim. An egg placed at the center would then quickly slide to the edge, where it would come to a standstill with its top pointing outward. If we made the surface only slightly concave, an egg placed near the rim moved towards the center of the cap. When one egg was already standing on the fluid on a horizontal surface, and we placed a second egg somewhere in its vicinity, the two eggs immediately moved towards each other. When we lifted the egg, still hanging from the capillary, the other egg moved away. When we pushed the egg a little into the solution, the other egg came closer. The slightest breath of air in our room usually made the various eggs placed on the surface to form a cluster, even though the distance between them could originally be as much as $1.5 \mathrm{~cm}$. Apparently an egg made a depression in the surface, which had an effect on the location where the other eggs came to rest. Single eggs placed on a sugar solution remained in a vertical position for several hours to more than a day, the time being longer when the sugar concentration we used was higher. When a minute droplet of diluted detergent was added to the surface of such a sugar solution, the egg instantly fell and rapidly submerged. This shows that the general forces of surface tension affect the equilibrium of the egg.

In conclusion, the secret of maintaining this equilibrium should lie in the fact that at places where the reticulate structure is present, small air bubbles tend to be captured as soon as such a place is submerged, thereby strongly reinforcing the effect of the lipophylic cell rims. As each singular cavity in the reticulate structure constitutes a new source of resistance for the fluid's flow, the front margin of the fluid undulates. The fluid progresses upward along the surface of the egg only in a jerky fashion, whereby the enclosed air bubbles near the margin easily reestablish contact with the atmosphere, thus forcing the fluid back from once submerged surface. The more tilted the position of the egg, the stronger is the effect of this safety belt.

When an egg remains in the center of a brood cell, the surface of the food must be perfectly horizontal. A brood cell of $M$. bicolor has a diameter of $5 \mathrm{~mm}$, far less than that of our vial caps. Nevertheless, except for the effect of froth the food surface is horizontal even to the point at which it reaches the cell wall. This means that the composition of the cerumen (a mixture of wax produced by the bee, and foreign admixtures such as plant resins), from which the cells are con- structed, is very well adjusted to the properties of the food and the biophysical needs of the egg. When we constructed an artificial brood cell from honeybee derived wax, the transferred larval food attained a very concave surface, and the transferred egg immediately fell down. Because the bottom part could move upwards along the slope of the fluid surface, the egg's center of gravity could reach a lower position. The froth, however, has an effect on the position of the egg. When gas bubbles come to the surface, they tend to aggregate along the cell wall. If enough bubbles are present, they cause the surface to take on a slightly concave shape, although originally it appears to be perfectly horizontal. It becomes horizontal again when the froth disappears. We conclude that an oblique position of the egg in its brood cell is related to the concavity of the surface of the larval food caused by the gas bubbles. In many species of stingless bees workers are able to lay eggs. These are of two types: alimentary and fertile eggs. An alimentary egg lacks the well-developed reticulate structure typical of a queen's egg, tumbles over, and sinks deep into the food, unless it sticks to the wall. The laying workers in a number of species of stingless bees in fact place their egg against the wall. We interpret this as an evolutionary adaptation, circumventing the inadequacy of the chorion. Other laying worker behavior may have been evolved from this, such as placing the alimentary egg at the cell rim (see [2] for comparative descriptions), and, as seen in Plebeia, the alimentary egg being deposited on the comb surface $[9,10]$. Such behavioral evolution is accompanied by a morphological differentiation of alimentary and fertile worker eggs, the alimentary eggs typically becoming spherical and having larger size. Fertile worker eggs, having a slightly developed reticulate structure, are often without sudden transition to the smooth basal part [8]. These eggs are generally laid after the queen's oviposition [11], and in this case two eggs occupy the same cell. In M. bicolor we observed them to cling to the queen's egg, thus gaining the necessary support. Without a well-developed chorion, with its sharp 
separation into a reticulate part able to capture air bubbles when partly submerged, and a smooth hydrophilic part to stand on, it is impossible to sustain a large portion of the egg well above the surface of a liquid larval food.

We thank Prof. Dr. Vera Lucia Imperatriz Fonseca for providing the bees, and Prof. Dr. Carminda da Cruz Landim for providing the neutral red stain. Mr. Gerard Stooker (Utrecht), and Mr. Eduardo T. Matos (São Paulo) provided substantial technical assistance, for which we express our gratitude. Financial support was given by FAPESP.

1. Michener CD (1974) The social behavior of the bees. Belknap, Cambridge
2. Sakagami SF (1982) Stingless bees. In: Hermann RH (ed) Social insects, vol III. Academic, New York, pp 361-423

3. Michener CD, Grimaldi D (1988) The oldest fossil bee: Apoid history, evolutionary stasis, and antiquity of social behaviour. Proc Natl Acad Sci USA $85: 6424-6426$

4. Hartfelder KH, Engels W (1989) The composition of larval food in stingless bess: evaluating nutritional balance by chemosystematic methods. Insectes Sociaux 36:1-14

5. Camargo CA de (1976) Dieta semi-artificial para abelhas da subfamília. Meliponinae (Hymenoptera, Apidae). Ciência e Cultura 28:430-431

6. Sommeijer MJ, van Zeijl M, Dohmen MR (1984) Morphological differences between worker-laid eggs from a queenright colony and a queenless colony of Melipona rufiventris paraensis (Hymenoptera: Apidae). Entomol Ber Amsterdam 44:91-95

7. Koedam D (1995) Behavioural and phys- iological implications of queen dominance in stingless bees. Thesis, University of Utrecht

8. Koedam D, Velthausz PH, van der Krift T, Dohmen MR, Sommeijer MJ (1996) Morphology of reproductive and trophic worker eggs and their controlled release by workers in Tetragonisca angustula (Apidae, Meliponinae). Physiol Entomol 21:289-296

9. Benthem FDJ van, Imperatriz Fonseca VL, Velthuis HHW (1995) Biology of the stingless bee Plebeia remota (Holmberg): observations and evolutionary implications. Insectes Sociaux 42:71-87

10. Drumond PM, Zucchi R, Mateus S, Bego L (1996) Oviposition behavior of the stingles bees, XVII. Plebeia (Plebeia) drorya$n a$ and an ethological comparison with other Meliponine taxa (Hymenoptera, Apidae). Jpn J Entomol 64:385-400

11. Beig D (1972) The production of males in queenright colonies of Trigona (Scaptotrigona) postica. J Apicultural Res 11:33-39

\section{Polarization Portrait of the Arago Point: Video-polarimetric Imaging of the Neutral Points of Skylight Polarization}

Gábor Horváth, József Gál, István Pomozi

Department of Biological Physics, Eötvös University, H-1088 Budapest,

Puskin u. 5-7, Hungary, e-mail: gh@hercules.elte.hu

\section{Rüdiger Wehner}

Zoologisches Institut, Universität Zürich, CH-8057 Zurich,

Winterthurerstrasse 190, Switzerland, e-mail: rwehner@zool.unizh.ch

Received: 29 December 1997 / Accepted in revised form: 8 April 1998

In 1809 the French astronomer Dominique Francois Jean Arago discovered the polarization of skylight [1]. Soon thereafter he observed a point of zero polarization in the sky [1], which nowadays is called the Arago neutral point. About 30 years later the French meteorologist Jacques Babinet found a second neutral point in

Correspondence to: G. Horváth the celestial hemisphere [2], and a few years later a third one was discovered by the Scottish physicist Sir David Brewster [3]. These neutral points have been the subject of many investigations in both the 19th and the 20th centuries [4-11]. In spite of their scientific popularity in atmospheric optics [5-11], until now they have not been able to be imaged due to the lack of proper wide-field polarimet- ers. We report here on the first polarization portrait of the Arago neutral point. In our video-polarimetric imaging study the spatial distribution of the degree and angle of polarization of the Arago point is presented in the red, green, and blue spectral ranges. The most important optical characteristics of the clear sunlit sky are well described by Rayleigh's theory [11]. The fine details of skylight polarization, however, differ from the ideal Rayleigh model. This failure, called the polarization defect, is caused by multiple scattering, molecular anisotropy, multi-order scattering by aerosol particles, size distribution and particle shapes of aerosol, and the light reflected from the ground. One of the most remarkable features of this defect is the phenomenon of the neutral points, where the polarization vanishes.

Under normal clear atmospheric conditions, the only neutral points of skylight polarization are the Arago [1], Babinet [2], and Brewster [3] points located in the plane of the sun's vertical (Fig. 1). These neutral points have been observed much more than any other characteristic of the skylight po- 